I TRADIÇÃO \& INOVAÇÃO • ESTÓRIA DE UM PIONEIRO 


\title{
ESTÓRIA DE UM PIONEIRO
}

\author{
NESTE ANO DE COMEMORAÇÃO, VALE CONHECER A TRAJETÓRIA DE GUSTAVO \\ DE SÁ E SILVA, PROFESSOR FUNDADOR E PRIMEIRO DIRETOR ELEITO DA \\ FGV-EAESP. SUA ENERGIA, DEDICAÇÃO, INTELIGÊNCIA E AMOR PELA ESCOLA \\ CONTRIBUIIRAM PARA A CONSOLIDAÇÃO E O PRESTÍGIO DA INSTITUIÇÃO
}

| POR MARIA IRENE STOCCO BETIOL + JACOB JACQUES GELMAN

\section{SELEÇÃO DE PROFESSORES}

Economista formado pela Fundação Álvares Penteado (FAAP), Gustavo trabalhava no departamento de Análises Econômicas e Estatística da General Motors do Brasil (GM) quando, em janeiro de 1954, tomou conhecimento e decidiu participar do concurso aberto pela Fundação Getulio Vargas (FGV) para a contratação de professores assistentes, com atuação em tempo integral, para uma nova Escola de Administração de Empresas de São Paulo (que seria a EAESP). Foi selecionado, juntamente com outros sete candidatos, dentre os quais estava seu chefe na GM, Raimar Richers, a quem convenceu a se inscrever no concurso.

Gustavo foi assistente dos primeiros professores da Michigan State University que vieram ao Brasil por conta de um acordo entre a FGV e o Ponto IV da USAID (governo norte-americano) - é possível encontrar mais informações sobre o assunto no artigo Guerra Fria e ensino do management no Brasil: o caso da FGV/EAESP, escrito por Rafael Alcadipani e Carlos Osmar Bertero e publicado na RAE-Revista de Administração de Empresas (v. 52, n. 3, 2012).

Ao longo dos oito meses que por aqui ficou, antes de embarcar para o seu mestrado nos Estados Unidos, envolveu-se com o novo projeto da Escola. Identificou-se com as ideias inovadoras dos professores da Missão Americana, com as metodologias de ensino e com o entusiasmo e a participação dos alunos do Curso Intensivo de Administração (CIA), o primeiro oferecido a empresários e executivos pela EAESP e que durava 13 semanas em regime de tempo integral.

Ao retornar ao Brasil, Gustavo começou a lecionar Marketing e Economia, juntando-se aos demais docentes brasileiros para participar da consolidação do curso de graduação em Administração de Empresas sob o comando de representantes da FGV e contando com a experiência dos professores americanos. Recheado de novidades, o novo curso - já com quatro anos de duração - transformou-se em um paradigma para as futuras escolas e universidades brasileiras nesta área.

“(...) Acabamos com os exames orais no vestibular, iniciamos o regime semestral e o de créditos. Decidimos que aqui não haveria catedráticos. (...) $O$ ingresso de alunos no Programa de Pós-Graduação em Administração, sem serem bacharéis em Administração, foi um espanto para os reitores em 1966. (...) Como ensino, era utilizado o método do caso, totalmente novo no Brasil".

Gustavo de Sá e Silva, 1992. 

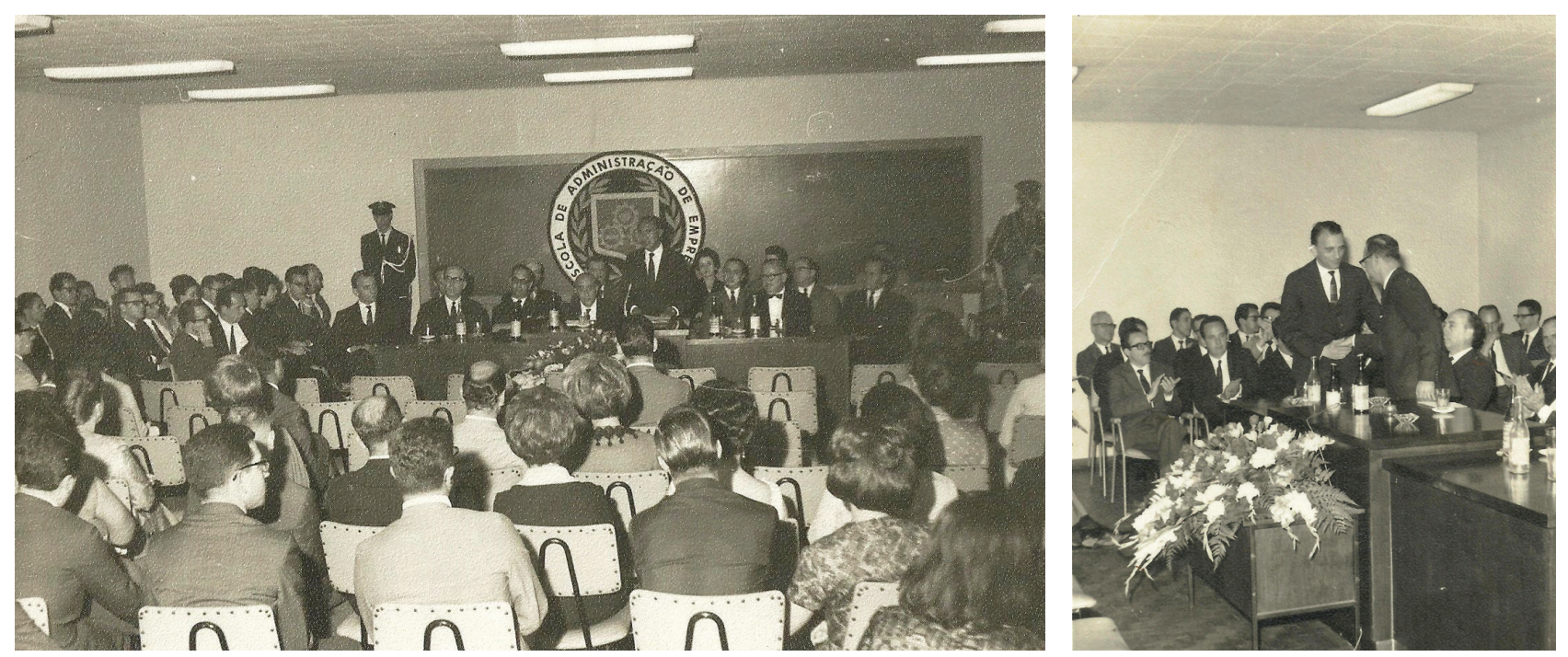

Posse de Gustavo de Sá e Silva como diretor da FGV-EAESP em 1964

\section{PRÓXIMO PASSO: DIRETORIA DA EAESP}

A eleição de Gustavo para diretor da Escola, em 1964, a primeira feita pela Congregação, órgão colegiado criado em 1959 e formado por professores e representantes dos alunos, foi um marco na história da EAESP. Até então a instituição vinha sendo dirigida por representantes designados pelo presidente da FGV, Luiz Simões Lopes. Aos professores de São Paulo foi transferida, a partir daí, a responsabilidade da condução futura da Escola. Gustavo, a essa altura, já havia conquistado o respeito e a confiança do presidente da Fundação, bem como a de seus principais assessores.

Ao longo dos seis anos seguintes, ele conduziu a Escola com total dedicação e entusiasmo, assegurando a preservação dos pilares de uma instituição formadora de "generalistas" e não de "especialistas", conforme a orientação dos professores da Michigan State University.

Formou seu grupo político - a famosa "panela" -, cujo núcleo duro continha brilhantes docentes, com igual paixão e dedicação à Escola. Pela lei natural, surgiu uma oposição ao grupo de Gustavo com o mesmo comprometimento para com a instituição. Para sorte dos alunos e da FGV, os embates políticos produziram decisões democráticas, bem como corajosas inovações. O Fundo de Bolsas, criado em 1965, é um bom exemplo disso.

Sob a liderança de Gustavo, foram estreitadas as relações com a comunidade empresarial paulista, fortalecendo o Conselho de Administração da Escola, criado em 1956.
A participação ativa dos empresários contribuiu significativamente para a arrecadação de recursos destinados ao Fundo de Bolsas. Uma escola que até então cobrava semestralidades simbólicas, passaria - para seu equilíbrio financeiro - a ser uma das mais caras de São Paulo. Todos os professores da EAESP se envolveram nesse projeto pioneiro, organizando encontros com empresários e ex-alunos em busca de recursos. Graças a esse Fundo, centenas de estudantes do curso de graduação conseguiram e conseguem completar seus estudos na Escola.

\section{UM LÍDER DEMOCRATA}

Gustavo, segundo depoimentos de alguns professores entrevistados para esta matéria, era um democrata por convicção, mantendo sempre o respeito por seus adversários políticos. Embora a "panela" fosse composta, em sua maioria, por docentes da esquerda, Gustavo não o era. Tinha grande autonomia e absoluta independência de pensamento. Inclusive, durante o regime militar em vigência, acolheu diversos professores perseguidos políticos, bem como defendeu a liberdade de manifestação dos alunos. Conta-se que chegou a ligar diretamente para o delegado Romeu Tuma, a fim de se certificar se um estudante detido estava recebendo tratamento respeitoso e se seria liberado imediatamente após seu depoimento.

Como professor, era exigente com os alunos, mas amigo no contato pessoal. Como diretor, gostava da proximidade com os jovens e os estimulava a participar do processo 


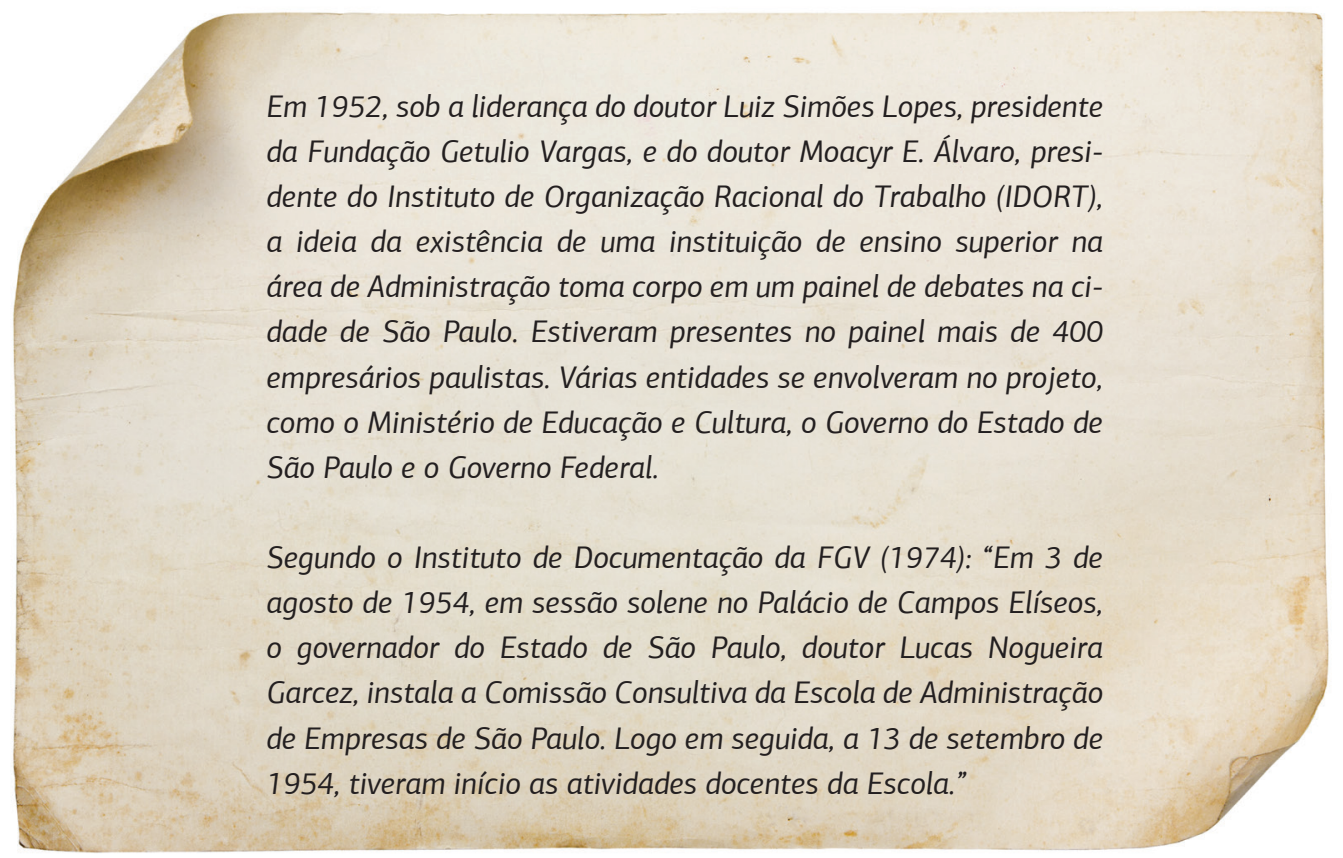

decisório da Escola, por meio de suas representações na Congregação e nos órgãos colegiados.

Apesar do bom relacionamento com a direção da FGV no Rio de Janeiro, não foram poucos os atritos e períodos críticos que teve que gerenciar e contornar.

Em 1974, no fim da gestão do professor Carlos José Malferrari, instala-se uma grave crise institucional entre a FGV e a EAESP, com a recusa do presidente Simões Lopes de nomear o primeiro e o segundo colocados nas eleições para a escolha do novo diretor. Assume o terceiro colocado, professor Ary Oswaldo Mattos Filho, que permanece poucos meses no cargo. AEAESP, então, negocia com a FGV, e a convocação de novas eleições garante a candidatura de Gustavo de Sá e Silva. Ele, que na época ocupava cargo na diretoria de uma empresa, recebeu a convocação e aceitou a missão, a fim de encerrar o conflito institucional. Durante quatro anos, Gustavo trabalhou em regime de dupla jornada, raramente saindo da Escola antes da meia-noite. Formou, nesse período, dois jovens docentes: Fernando Gomes Carmona e Alain Stempfer, seus vice-diretores que, em gestões posteriores, chegaram à diretoria.

\section{ÚLTIMOS 15 ANOS NA EAESP}

Deixando a diretoria no fim da década de 1970, Gustavo foi sucedido por Fernando Carmona. Apesar disso, ainda manteve suas atividades docentes e políticas por mais 15 anos na EAESP.

Ocupou importantes cargos em empresas estatais, nos governos Montoro e Covas, e participou intensamente das grandes transformações ocorridas na Escola. Esteve ao lado de todos os diretores, sempre pronto para ajudar e manter elevado o conceito da instituição. Sentia um enorme orgulho da casa!

Gustavo foi prestigiado até o fim de sua vida por todos os presidentes da FGV, como demonstração de reconhecimento e respeito por sua competência e comprometimento institucional.

"Aqui ganhei importante experiência de vida. Olho para trás e lembro de minha vida com bastante satisfação e tranquilidade; percebo que participei ativamente de alguma coisa relevante neste país. Minha vida na Escola foi bem-sucedida e sempre pude manter intocável o que acho que foi importante: o respeito por mim mesmo, pelos outros e dos outros. E isso não se compra com dinheiro".

Gustavo de Sá e Silva, 1992.

Com essas lembranças, estendemos a homenagem a todos os docentes pioneiros da EAESP.

Agradecemos especialmente a Alain Stempfer, Álvaro da Silva, Fernando Carmona e Paulo Goldschmidt, professores da EAESP, e Marli Griesi Camargo, secretária de Gustavo de Sá e Silva, pelos depoimentos concedidos, os quais permitiram a composição deste artigo.

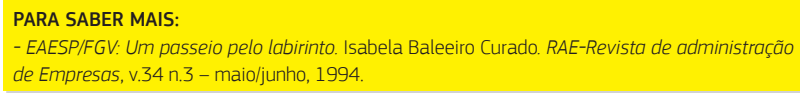

MARIA IRENE STOCCO BETIOL > Editora convidada da GV-executivo > misbetiol@gmail.com JACOB JACQUES GELMAN > Professor da FGV-EAESP > jacques.gelman@fgv.br 